the sea each year (K.J. Whittle, MAFF Torry Research Station, Aberdeen). None of the following contributors who described the biological effects of oil defined what they meant by 'long term' and it was left to the penultimate speaker, Sir Hans Kornberg, FRS (Chairman Emeritus of the Royal Commission on Pollution) to quantify this term when he referred to the preceding papers as discussing "serious short term effects'. Evidently the Royal Commission must regard long term as periods greater than the 10 to 20 years mentioned during the meeting as the time needed for recovery by some ecosystems after oil spills. In contrast, most of the contributors evidently thought that 10 to 20 years was a long time in comparison with the severe mortalities that ensue a few hours or days after major and minor spills (J.H. Vandermeulen, Bedford Institute of Oceanography, Dartmouth, N.S.).

It was suggested that repeated oil spills on one coast, such as in Brittany since 1967 , might put off final recovery of affected communities to the next century (A.J. Southward, Marine Biological Association, Plymouth), but this was thought too pessimistic by the chairman (R.B. Clark, University of Newcastle) who noted that communities and ecosystems were remarkably resilient. This appears to be true for sea-birds, which suffer the most distressing casualties seen by the public, but which are mostly long-lived species undergoing heavy natural mortality each year, when hundreds of thousands die compared with tens of thousands killed by oil (G.M. Dunnett, University of Aberdeen). As confirmed in the discussion (W.R.P. Bourne, University of Aberdeen), some species can make up for heavy mortality in colonies by accelerated maturation of the juveniles.

Marine fishes suffer much heavier

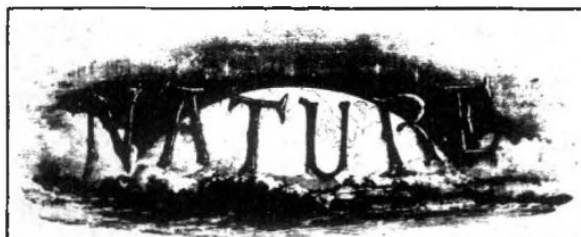

99 years ago

WEATHER FORECASTS

1 have recently designed and patented "An improved floating vessel for automatically compressing air by the action of the waves of the sea, and also for the generation of electricity by the agency of this compressed air." This vessel is capable of being moored in 1000 fathoms, and can be connected with the shore by means of an insulated electric cable. Such a vessel moored in the mid-Atlantic in the usual track of the cyclones which approach these islands from the west, would be of immense advantage to the Meteorological Office in determining the velocity of advance and direction taken by these cyclonic centres. I purpose exhibiting a model and drawings of the vessel at the Winter Electric Exhibition, to be held at the Westminster Aquarium next month. CHARLES W. HARDING natural mortalities than birds during their life history, and are also subjected to heavy pressure from fisheries. Fish populations, and catches by fishermen, undergo extensive natural fluctuations which, without the records of fishery statistics, might be ascribed to pollution rather than to natural changes or overfishing ( $R$. Jones, DAFS Marine Laboratory, Aberdeen). Other marine populations, inlcuding those on the seashore, undergo extensive natural fluctuations, and it may be difficult to detect pollution effects (J.R. Lewis, Wellcome Marine Laboratory, Robin Hood's Bay, Yorkshire). No general signs of oil-induced mortalities have been detected in commercial fish stocks (A.D. McIntyre, DAFS Marine Laboratory, Aberdeen), but tainting of the flesh may be evident after spills, and there is some suggestion of local inshore population changes in oysters and shrimp, related to chronic oil pollution. Other shellfish, especially Mytilus, are weil known to be sensitive to low levels of petroleum hydrocarbons or other forms of sublethal environmental stress (B.L. Bayne, Institute for Marine Environmental Research, Plymouth), which can be detected as changes in metabolism and gonad development. It is therefore surprising that little general effect of natural oil seeps can be demonstrated in the Mytilus californianus community around Santa Barbara (Dale Straughan, Institute for Marine and Coastal Studies, University of Southern California, Los Angeles). Offshore petroleum operations in the Gulf of Mexico also appear to have had little effect on shell fisheries and the bottom fauna in general (J.M. Sharp, Gulf Universities Research Consortium, Houston), but signs of pollution-induced changes in the benthos are appearing close to a North Sea oil-rig (J.P. Hartley, Orielton Field

\section{THE MAGNETIC STORM AND AURORA}

The telegraphic system of this country has, since Friday morning last, been disturbed in a way that far exceeds anything of the kind that has ever happened before. Very powerful electric currents have been swaying backwards and forwards through the crust of the earth, taking all telegraphic circuits in their progress, and entirely stopping communication. Communication has been maintained only where it was possible to loop together two wires, so as to avoid the use of the earth altogether. The electric storm commenced on Thursday, but it reached its climax on Friday morning (November 17) between 10 and 11 a.m. The currents measured over 50 milliampéres, which is five times greater than the ordinary working currents. They have repeated themselves at intervals ever since, but have scarcely attained such an intensity as on Friday morning.

Both the storm and the aurora seem to have extended to America; the Philadelphia correspondent of the Times telegraphs under date November 19:-

"The electrical storm which began to derange the telegraph wires on Friday last still continues, though with less intensity. It spread

\section{Centre, Pembroke).}

Nevertheless, there is abundant experimental and circumstantial evidence that oil pollution is associated with histopathological lesions in fish and genetical abnormalities in pelagic eggs and larval stages (C.J. Sindermann, NOAA, Sandy Hook Laboratory, New Jersey). Such effects were seen in flatfish after the 'Amoco Cadiz' spill in Brittany (M. Conan, CNEXO, Brest), where long-lasting retention of oil in fine sediments may be delaying recovery of benthic animals and salt-marshes. It was thought that some saltmarshes, which were damaged by clean-up measures as well as oil, may take 20 years to recover. Comparable lengths of time have been suggested for tropical mangrove communities, which are very sensitive to oil damage (J. Baker, Orielton Field Centre, Pembroke). Both these types of community tend to be in places where oil spills are more likely.

The meeting demonstrated that there are long term chronic effects of oil, even if the evidence is partly circumstantial; but although damage from accidental spills can be severe and take many years to repair, the general effects are not as bad as once feared. It was felt that the tendency for committees to recommend further experiments on detection of effects of oil pollution should be resisted and replaced with ecological monitoring having well defined motives and objectives: there should be no hesitation in abandoning or reducing surveys where no ill effects were apparent. It is hoped that the recommendations of the Royal Commission will be acted upon by the Government, particularly those concerned with the prevention of oil spills, searches for clean-up techniques not dependent on chemicals and the setting-up of a central unit for coordinating action after spill.

through Canada and the greater part of the United States, as far west as Utah. The electricians say that the disturbance was unlike any heretofore known, acting upon the wires in strong waves, which produced constant changes in the polarity of the current. A magnificent aurora appeared on Friday night and was visible at all points, except where clouds obscured it. Cold weather, with snow, accompanied the storm in many places."

Mr W.H.M. Christie, the Astronomer Royal, writes -

In the evening, as soon as it was dark, a brilliant aurora was seen, commencing with a bright glow of red light extending from the north and west beyond the zenith, interspersed with pale green phosphorescent light and streamers. At $6 \mathrm{~h} .4 \mathrm{~m}$. a very brilliant streak of greenish light about $20^{\circ}$ long appeared in the east-north-east, and, rising slowly, passed nearly along a parallel of declination, a little above the moon, disappearing at $6 \mathrm{~h} .5 \mathrm{~m} .59 \mathrm{~s}$. in the west, about two minutes after it was first seen. The whole aurora had faded away by about $7 \mathrm{~h}$., but it burst out again at $11 \mathrm{~h} .45 \mathrm{~m}$., when an auroral arch, with brilliant streamers reaching nearly to the zenith, was seen from north-north-east to north-west.

From Nature 27, 79 \& 82, November 23, 1882. 